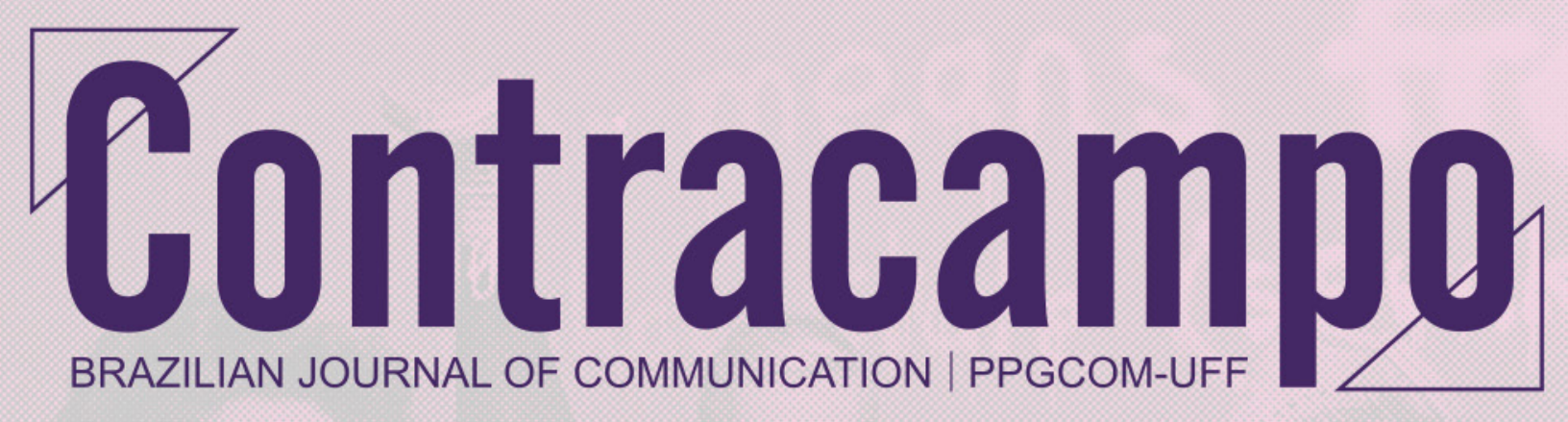

VOLUME 38. NÚMERO 1. 2019. E-ISSN 2238-2577. ABR-JUL2019

\title{
DOSSIE
}

G
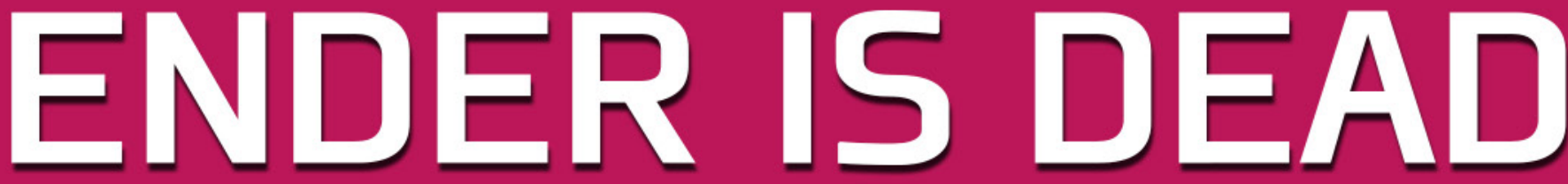

PINK IS FOREVER.

IDENTIDADES DE GÊNERO,

DIFERENÇAS E CULTURAS

DO-IT-YOURSELF 


\section{Gender is Dead. Pink is Forever. Identidades de gênero, diferenças e culturas do-it-yourself}

As questões de gênero afortunadamente têm-se tornado um tópico de crescente interesse no âmbito da pesquisa sobre cenas musicais e artísticas contemporâneas. Porém, este crescimento tem sido bastante lento. E se nos reportarmos aos anos 1970 e 1980, um período de grande produção teórica em torno dos estudos subculturais, percebemos uma quase completa ausência da temática. Dizemos quase completa ausência, pois no panorama dos estudos do Centre for Contemporary Cultural Studies (CCCS) as mulheres apareciam - ainda que reproduzindo papéis sexualizados: ou eram namoradas ou simples conquistas sexuais (BRAKE, 1985). É com a pesquisadora Angela McRobbie que esta questão começa inicialmente a ser combatida. Destacando a ausência de temáticas como a sexualidade e o gênero nos estudos das subculturas inglesas e criticando a falta de suporte empírico de muitos estudos, Mc Robbie levantou problemas metodológicos cruciais, tais como o fascínio dos investigadores por subculturas masculinas e a sua identificação com as atitudes misóginas de seus informantes, além da reprodução dos valores patriarcais nas investigações (MCROBBIE; GARBER, 1997).

As críticas desencadearam o desejo de "encontrar" as mulheres e desta forma acabar com a sua invisibilidade, o que implicou também o repensar de um conjunto de conceitos e metodologias (GUERRA et al., 2018). Pois, seria correto colocar no mesmo patamar situações materiais distintas de homens e mulheres? Por exemplo, omite-se a questão das garotas não conseguirem ter uma participação subcultural, primeiramente devido ao fato de que tinham menos dinheiro disponível do que os rapazes; segundo, porque o conjunto de suas obrigações domésticas implicava em menos tempo livre disponível. De igual modo, a velha distinção entre espaço público/privado ainda prevalecia no ambiente do pós-guerra e início dos anos 1960, no qual pairavam sobre as mulheres que andavam fora de casa os medos e estigmas de se tornarem "mal faladas" e colocarem em risco o bom-nome da família (GOTTLIEB; WALD, 1994). Isto posto, McRobbie e Garber (1997) concordam que a participação subcultural feminina é menor que a masculina pelo menos nos moldes que usualmente se analisa essa participação. Porém, esta questão também exige uma reformulação de perspectiva, a fim de percebermos a participação feminina como qualitativamente diferente, mais focada, por exemplo, no espaço doméstico, através do consumo de álbuns, revistas e pôsteres de seus ídolos (MCROBBIE, 1991) ou no uso da moda como um contradiscurso face às restrições encontradas na escola.

Na década de 1990, trabalhos focados na subcultura rave novamente constatam a invisibilidade feminina, tais como o de Thornton (1995), sublinhando os papéis periféricos que eram reservados às mulheres, impedidas de subir na hierarquia subcultural, apesar dos valores pretensamente igualitários desta cena inglesa. E numa perspectiva ainda mais recente e próxima à realidade do-it-yourself, Griffin (2012), na sua análise de uma cena punk DIY inglesa, constata que além de existirem poucas bandas com mulheres, existe ainda outro fator relevante: são os homens que detêm o monopólio da organização de concertos, posição que determina o tipo de discurso que se estabelece na cena e sobretudo a narrativa 
memorialística sobre a mesma, fazendo com que as poucas mulheres "desapareçam" no momento em que o passado se torna história (STRONG, 2011). Um dos motivos é o fato de as mulheres não estarem envolvidas no processo de registro da memória da cena - o record keeping (KLEINBERG, 1988) e, por outro lado, uma incapacidade de controlarem a linguagem e os símbolos usados para reproduzir as estruturas de poder.

No processo de rotulação e de disputa simbólica, vale ainda notar como determinados termos são apropriados e virados do avesso. Nos anos 1990, surgiu o riot grrrl, movimento musical de viés feminista baseado no ethos DIY e numa lógica de questionamento das experiências de sexismo e secundarização que as mulheres viviam no mundo da música (BENNETT; GUERRA, 2019). O problema é que o termo foi apropriado pela crítica musical para definir toda e qualquer artista e ainda como elemento de distinção entre grunge e riot grrrl. O primeiro tido como mais "nobre" (e masculino) e o segundo como um rótulo conveniente para se aplicar a toda e qualquer banda feminina desta época (STRONG, 2011, p. 408).

Para o âmbito deste dossiê, é necessário ainda mencionar as novas ondas do feminismo, que especialmente a partir dos anos 1970 tem recebido novas perspectivas e cosmologias vindas de atores até então subalternizados: negras, lésbicas, transexuais, pobres, etc. Cruzando-se com as perspectivas pós-coloniais, este novo feminismo questiona e amplia a pauta da discussão encaminhada por ativistas brancas, heterossexuais e de classe média, reivindicando a necessidade de articulações mais complexas entre gênero e etnia.

Aproveitando este ensejo e tomando em consideração este complexo cenário envolvendo a temática das identidades e diferenças de gênero, num contexto em que a relação das artes e da música com as esferas sociais, culturais e políticas compõem uma plataforma de investigação bastante fecunda, assim como nos oferece a possibilidade de consolidação de um domínio de conhecimento que responda aos desafios e mudanças alicerçado na cultura das redes, fluxos e transações que caracterizam os campos e as cenas musicais e artísticas contemporâneas, os editores convidados se orgulham de apresentar aos leitores um conjunto de artigos que abordam estas questões em múltiplas perspectivas.

No artigo Presença e atuação de mulheres em espaços culturais no Rio de Janeiro do século XIX: o que podem as mulheres em festa?, as autoras Cíntia Sanmartin Fernandes (UERJ) e Flávia Magalhães Barroso (UERJ) apresentam uma abordagem histórica que privilegia os relatos sobre a presença e atuação de mulheres, sobretudo de mulheres negras, em festividades no Rio de Janeiro no século XIX, destacando as subversões temporárias das posições "subalternizadas" da cultura negra e das mulheres em momentos de festa. Segue-se o artigo Diva da sarjeta: ideologia enviadescida e blasfêmea pop-profana nas políticas de audiovisibilidade da travesti paulistana Linn da Quebrada, no qual Rose de Melo Rocha (ESPM) e Aline Rezende (ESPM) analisam algumas das formas de resistência mobilizadas pela artista, performer, bailarina e cantora paulistana Linn da Quebrada, atentando para modos de ocupar as cidades e as redes sociais que re-significam corpos, espaços midiáticos e vida cotidiana.

O terceiro artigo do dossiê, Don't be a drag, just be a queer: Lady Gaga e semiodiversidade em redes digitais do jornalismo de cultura pop, de Ronaldo Henn (Unisinos) e Christian Gonzatti (Unisinos), propõe uma análise dos sentidos acionados por notícias relacionadas a Lady Gaga no jornalismo de cultura pop brasileiro e nas redes sociais, tendo como objetivo entender o que eles sinalizam sobre questões de gênero e sexualidade, compreendidas em uma perspectiva queer. Também no artigo seguinte, $E$ nessa cena a vovó da Pabllo já era transgressora: performances queer na música pop brasileira, de Carlos Magno Camargos Mendonça (UFMG) e Felipe Viero Kolinski Machado (UFOP), a temática queer é o foco, a partir da discussão sobre performances musicais que aproximam artistas do teatro e da música dos anos 1970 e da cena musical pop contemporânea brasileira, em produções que colocam em questão os limites impostos pelos papéis sociais de gênero; que denunciam o patrulhamento heteronormativo sobre os corpos; e que investem na visibilização de identidades fluidas e diversas. O quinto artigo, Minha língua é minha pátria? 
A circulação de artistas "multiculturais" na cena dos festivais na cidade de Montreal (Canadá), de Nadja Vladi Gumes (UFRB), introduz uma outra temática ao debate, discutindo o papel da música para a inclusão de migrantes. Fruto de sua pesquisa de pós-doutorado realizado na cidade de Montreal, no Canadá, a autora aborda o funcionamento dos festivais como parte do circuito para a circulação desses artistas com o objetivo de difundir sua arte, demonstrando como essa rede de festivais canadense possibilita a criação de um networking com produtores, empresários e jornalistas.

Os dois artigos seguintes abordam o protagonismo feminino em duas cenas musicais bastante distintas. Jongo, Substantivo Feminino, Em Cenas Musicais, de Maria Livia de Sá Roriz (UNIVERSO), aborda as rodas de jongo contemporâneas na cidade do Rio de Janeiro, destacando o fato de as mulheres terem assumido, sobretudo a partir do início dos anos 2000, papéis antes exclusivos dos homens nesse cenário, tais como tocar os tambores sagrados e desafiá-los no canto; e Keep on moving Mujeres DJs en la escena electrónica de la ciudad de Córdoba, de Gustavo Alejandro Blázquez (UNC/Argentina) e Rocío María Rodríguez (UNC/Argentina), abordam as práticas de DJs mulheres da cena eletrônica da cidade de Córdoba, na Argentina, a partir de perspectivas etnográficas. E a seguir, debate-se a contribuição dos videoclipes de Madonna na década de 1980 e 1990 para a desconstrução de hierarquias de gênero, tema do artigo Urban simulacrum and Madonna: the post-modern environment of music video, de Roney Gusmão (UFRB) e Sérgio Araújo (ESE/Portugal), no qual os autores sublinham o protagonismo da diva pop na construção de uma estética urbana e contemporânea.

Dois artigos têm por foco a produção latino-americana e encerram o dossiê. Um, intitulado Música y feminismo espiritual. Conceptos y estéticas religiosas en propuestas musicales recientes de artistas mujeres, de Mercedes Liska (UBA/Argentina), aborda as obras de quatro artistas argentinas que têm em comum a articulação entre o feminismo e o sagrado, através de um conjunto de representações religiosas que, segundo a autora, contribuem para visualizar os poderes femininos silenciados pelo sistema patriarcal. O outro, O bolero de um migrante fracassado: consumo e fracasso em No Quiero Quedarme Sola Y Vacia, de Ricardo Duarte Filho (UFRJ), discute a questão do fracasso e migração queer a partir do romance No Quiero Quedarme Sola Y Vacia (2006), de Angel Lozada, propondo uma leitura queer da obra que "nos permite pensar linhas de fuga ao discurso liberal do bom imigrante como aquele que ajuda o país a prosperar."

Além do dossiê, a presente edição da Revista Contracampo traz ainda um artigo na seção de temáticas livres: Comunicação digital, economia de dados e a racionalização do tempo: algoritmos, mercado e controle na era dos bits, de autoria de Sivaldo Pereira da Silva (UFS), que enreda uma discussão sobre os processos de datificação da vida na comunicação digital, observando como a noção de tempo é tratada pela emergente economia baseada em dados.

Através desta multiplicidade de abordagens, esperamos contribuir para o debate em torno das identidades, práticas e performances de gênero em perspectiva comunicacional e dos estudos culturais, amplificando as vozes, as perspectivas e as controvérsias. Boa leitura!

Simone Pereira de Sá, Universidade Federal Fluminense, Brasil

Paula Guerra, Universidade do Porto, Portugal

Jeder Janotti Júnior, Universidade Federal de Pernambuco, Brasil

Editores-convidados 


\section{Referências:}

BENNETT, Andy \& GUERRA, Paula (eds.). DIY Cultures and Underground Music Scenes. Abingdon/Oxford: Routledge, 2019.

BRAKE, Mike. Comparative Youth Culture: The Sociology of Youth Cultures and Youth Subcultures in America, Britain and Canada. Londres: Routledge, 1985.

GOTTLIEB, Joanne \& WARD, Gayle. Smells like teen spirit: riot grrrls, revolution and women in independent rock. In A. ROSS \& T. ROSE (orgs.). Microphone fiends: youth music and youth culture (pp. 250-274). Nova lorque/Londres: Routledge, 1994.

GRIFFIN, Naomi. Gendered Performance Performing Gender in the DIY Punk and Hardcore Music Scene. Journal of International Women's Studies, v. 13, n. 2. p. 66-81, 2012.

GUERRA, Paula; Bittencourt, Luiza \& Gelain, Gabriela. "Punk Fairytale”: Popular Music, Media, and the (Re) Production of Gender. In M. TEXLER SEGAL \& V. DEMOS (eds.). Gender and the Media: Women's Places. (pp. 49 -68). Bingley: Emerald Publishing, 2018.

KLEINBERG, S. J. Retrieving Women's History: Changing Perceptions of the Role of Women in Politics and Society. New York: Berg, 1988.

MCROBBIE, Angela \& GARBER, Jenny. Girls and Subcultures. In K. GELDER \& S. THORNTON (orgs.). The Subculture Reader (pp. 112-120). Londres: Routledge, 1997.

MCROBBIE, Angela. Feminism and Youth Culture: From Jackie to Just Seventeen. Boston: Unwin Hyman, 1991.

STRONG, C. Grunge, Riot Grrrl and the Forgetting of Women in Popular Culture. The Journal of Popular Culture, v. 44, n. 2, p. 398-416, 2011.

THORNTON, Sarah. Club Cultures: Music, Media and Subcultural Capital. Cambridge: Polity, 1995. 


\section{EQUIPE EDITORIAL}

\section{Editoras-chefes}

Ariane Holzbach (UFF)

Thaiane Oliveira (UFF)

\section{Editores-convidados}

Simone Pereira de Sá (UFF)

Paula Guerra (UPorto)

Jeder Janotti Júnior (UFPE)

Editores-executivos

Luana Inocêncio (coordenadora)

Caio Melo

Gabriel Ferreirinho

Lumárya Souza

Paula Fernandes

Renata Menezes Constant

Seane Melo

Revisão

Jonas Pilz (coordenador)

Ana Luiza Figueiredo

Ana Paula Barros

Erly Guedes

Manuela Arruda Galindo

Rodrigo Quinan

Verônica Lima

\section{Tradução / Versão}

Patrícia Matos (coordenadora)

Deborah Santos

Jessika Medeiros

Leonam Dalla Vecchia

Matheus Bibiano

Projeto gráfico / Diagramação

Érica Ribeiro (coordenadora)

Luiza Costa

Foto de capa

Esgar Acelerado

Planejamento estratégico

Lumárya Souza (coordenadora)

Angélica Fonseca

Camilla Quesada Tavares

Daniela Mazur

Ícaro Joathan

Ledson Chagas

Melina Meimaridis

Comunicação

Pollyane Belo (coordenadora)

Lucas Bragança

Nayara Amaral 